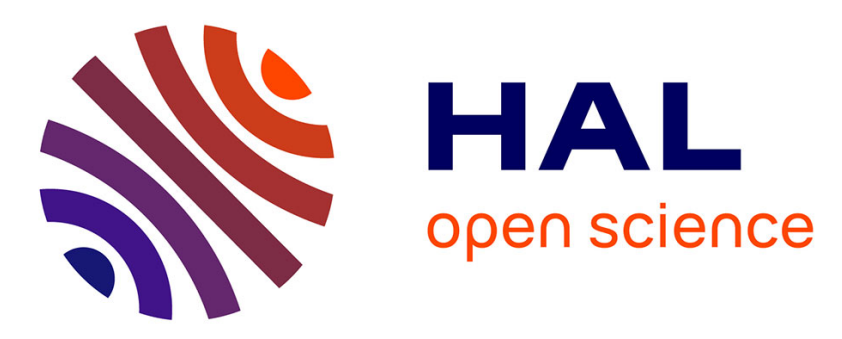

\title{
Bent HgI2 Molecules in the Melt and Sulfide Glasses: Implications for Nonlinear Optics
}

\author{
Mohammad Kassem, Maria Bokova, Andrey S. Tverjanovich, Daniele
}

Fontanari, David Le Coq, Anton Sokolov, Pascal Masselin, Shinji Kohara, Takeshi Usuki, Alex C. Hannon, et al.

\section{To cite this version:}

Mohammad Kassem, Maria Bokova, Andrey S. Tverjanovich, Daniele Fontanari, David Le Coq, et al.. Bent HgI2 Molecules in the Melt and Sulfide Glasses: Implications for Nonlinear Optics. Chemistry of Materials, 2019, 31 (11), pp.4103-4112. 10.1021/acs.chemmater.9b00860 . hal-02177797

\section{HAL Id: hal-02177797 https://hal-univ-rennes1.archives-ouvertes.fr/hal-02177797}

Submitted on 10 Sep 2019

HAL is a multi-disciplinary open access archive for the deposit and dissemination of scientific research documents, whether they are published or not. The documents may come from teaching and research institutions in France or abroad, or from public or private research centers.
L'archive ouverte pluridisciplinaire HAL, est destinée au dépôt et à la diffusion de documents scientifiques de niveau recherche, publiés ou non, émanant des établissements d'enseignement et de recherche français ou étrangers, des laboratoires publics ou privés. 


\begin{abstract}
Non-linear optical (NLO) crystals are widely used in advanced photonic technologies for second harmonic and difference frequency generation (SHG and DFG, respectively), producing coherent light at frequencies where existing lasers are unavailable. Isotropic glasses do not exhibit SHG or DFG, except temporary induced anisotropy under external stimuli. However, recent reports on glasses with chiral structural motifs show promising permanent NLO properties. We propose an alternative solution: hybrid molecular/network glasses with non-centrosymmetric $\mathrm{HgI}_{2}$ monomers. Mercury (II) iodide consists of linear $\mathrm{HgI}_{2}$ triatomic molecules in the vapor phase and in the yellow orthorhombic polymorph stable above $400 \mathrm{~K}$. At lower temperatures, the tetragonal red form is composed of corner-sharing $\mathrm{HgI}_{4 / 2}$ tetrahedra forming a layered extended framework. There is a gap in the molecular evolution; direct structural measurements of the liquid $\mathrm{HgI}_{2}$ phase are missing. Using high-energy $\mathrm{X}$-ray scattering, pulsed neutron diffraction and Raman spectroscopy supported by structural and vibrational modeling, we show that the mercury (II) iodide melt and $\mathrm{HgI}_{2}$-containing sulfide glasses are built-up by bent $\mathrm{HgI}_{2}$ monomers (the bond angle $\angle \mathrm{I}-\mathrm{Hg}-\mathrm{I}=156 \pm 2^{\circ}$ in the melt). The non-centrosymmetric entities imply intrinsic optical non-linearity of the second order, confirmed by a strong SHG response.
\end{abstract}




\section{INTRODUCTION}

Infrared spectral range between 2 and $25 \mu \mathrm{m}$ is a fingerprint region for optical sensing of chemical species in environmental monitoring, bio-medical applications, industrial process control and security. Tunable coherent light sources operating within mid-IR range and beyond need a new generation of non-linear optical (NLO) materials for efficient frequency conversion using second harmonic and difference frequency generation (SHG or DFG, respectively). Metal chalcogenides with a wide energy gap are the most promising materials for NLO applications in this range. ${ }^{1}$ Cutting-edge technologies and devices need large optical single crystals, fibers and thin films often representing difficulties in synthesis and elaboration. Versatile glassy materials can be an excellent choice to avoid bottlenecks in practical applications. Isotropic glasses do not exhibit SHG or DFG because of the presence of inversion symmetry at the macroscopic level, except temporary induced anisotropy under external stimuli (thermal and optical poling, electron beam irradiation). However, recent reports on glasses with chiral structural motifs show promising permanent NLO properties. ${ }^{2-4}$ We propose an alternative solution: hybrid molecular/network glasses with non-centrosymmetric $\mathrm{HgI}_{2}$ molecules. Nevertheless, the first question was whether $\mathrm{HgI}_{2}$ entities are non-centrosymmetric in the melt and respective glasses as solidified supercooled liquids out of thermodynamic equilibrium.

Mercury (II) iodide $\mathrm{HgI}_{2}$ has been extensively studied over the last few decades owing to multiple applications in room-temperature X-ray and gamma-ray detection;5,6 it is particularly useful for flat panel medical imaging technologies.7, $\mathrm{HgI}_{2}$ also has promising optical properties $^{9,10}$ and creates a vivid interest in a fundamental field. ${ }^{11-13}$ The mercury (II) iodide vapor consists of linear $\mathrm{HgI}_{2}$ triatomic molecules confirmed by gas-phase electron diffraction ${ }^{14,15}$ and Raman spectroscopy. ${ }^{16-18}$ Basically, the enhanced stability of the $D_{\infty h}$ symmetry for $\mathrm{HgI}_{2}$ and Group 12 dihalides is related to their electronic structure, relativistic effects and the $d$-block (Zn, $\mathrm{Cd}$ ) or lanthanide $(\mathrm{Hg})$ contraction. ${ }^{11-13}$ The $\mathrm{HgY}_{2}$ linear molecules, where $\mathrm{Y}=\mathrm{Cl}, \mathrm{Br}$, I, were considered to be exceptionally rigid as a result of the large relativistic contraction of their $s$ orbitals. ${ }^{13}$ In the solid state, the molecular nature and linearity of mercury (II) iodide are partly broken. Red $\mathrm{HgI}_{2}$, stable at ambient conditions, and metastable orange polymorphs consist of corner-sharing $\mathrm{CS}-\mathrm{HgI}_{4 / 2}$ tetrahedra. ${ }^{19,20}$ In the tetragonal red $\alpha-\mathrm{HgI}_{2}$ form, space group $\mathrm{P}_{2} / \mathrm{nmc}$, the $\mathrm{CS}-\mathrm{HgI}_{4 / 2}$ entities form 2D-layers with a van der Waals interlayer gap of $4.14 \AA$. Three distinct orange polymorphs consist of corner-sharing CS- $\mathrm{Hg}_{4} \mathrm{I}_{6} \mathrm{I}_{4 / 2}$ adamantane-like superstructural tetrahedral units forming either a polytypical layer structure or two interpenetrating diamond-type networks. ${ }^{21,22}$ Above $400 \mathrm{~K}$, both the stable red and metastable orange forms exhibit a first-order phase transition into molecular yellow form. The metastable at room temperature yellow polymorph can also be obtained by sublimation and/or from organic solvents. ${ }^{19,20,23}$ Orthorhombic yellow $\beta-\mathrm{HgI}_{2}$, space group $\mathrm{Cmc} 2_{1}$, consists of almost linear triatomic molecules with the I-Hg-I bond angle of $178.3 \pm 0.3^{\circ} .19$ This $\beta$-polymorph was prepared by sublimation and measured at room temperature. The crystal structure of $\beta-\mathrm{HgI}_{2}$ obtained from a saturated mercury (II) iodide solution in 2-chloroethanol at room and elevated temperatures was found to be nearly identical, however, the molecules are linear, $\angle \mathrm{I}-\mathrm{Hg}-\mathrm{I}=$ $180.0 \pm 0.4^{\circ} .23$ In contrast, the synchrotron diffraction measurements at $412 \pm 2 \mathrm{~K}$ have shown a monoclinic version of yellow mercury (II) iodide, $\beta^{\prime}-\mathrm{HgI}_{2}$, space group $P 2_{1}{ }^{23}$ The triatomic molecules are bent in the monoclinic yellow polymorph, $\angle \mathrm{I}-\mathrm{Hg}-\mathrm{I}=160 \pm 3^{\circ}$, confirmed also by Raman spectroscopy ${ }^{18}$ and the second harmonic generation. ${ }^{23}$ The third yellow polymorph, $\mathrm{HgI}_{2}$-VI, was observed at high pressure $P \geq 1.3 \mathrm{GPa}$ both at room and elevated temperatures..$^{20,24}$ 
The Raman spectroscopy measurements ${ }^{25,26}$ suggested similar but not identical structure compared to yellow $\beta-\mathrm{HgI}_{2}$. Nevertheless, the Bragg peaks above $1.3 \mathrm{GPa}$ became very broad, limiting the structural information that could be extracted.24 The molecular structure of mercury (II) iodide melt is incomplete. The Raman spectroscopy measurements ${ }^{18,27}$ suggest nonlinear $\mathrm{HgI}_{2}$ molecules but the diffraction studies are missing.

The main goal of the present contribution is to reveal the atomic structure in liquid mercury (II) iodide following the molecular architecture from the extended framework of a stable solid at low temperatures to a molecular vapor in the high- $T$ range. Additionally, we are interested to compare the liquid $\mathrm{HgI}_{2}$ structure with the short and intermediate range order in $\mathrm{HgI}_{2}$ containing sulfide glasses as frozen supercooled liquids bearing in mind their possible applications in non-linear optics. High energy X-ray scattering, pulsed neutron diffraction and Raman spectroscopy supported by structural and vibrational modeling were used to unveil structural features of the stable liquid and related glassy solids.

\section{EXPERIMENTAL SECTION}

Glass Preparation. Commercial mercury (II) iodide (Sigma-Aldrich, $99.999 \%$ ) was used without any additional purification. The high vapor pressure oxide contaminants in elemental arsenic (Cerac, $99.9999 \%$ ) were removed by evaporation at $600 \mathrm{~K}$ in vacuum. Sulfur pellets (Acros Organics, 99.999\%) were heated to $400 \mathrm{~K}$ under vacuum, then sealed and distilled at 700 $\mathrm{K}$. The synthesis of $\mathrm{As}_{2} \mathrm{~S}_{3}$ was carried out in evacuated silica tubes at $1050 \mathrm{~K}$ using a rocking furnace before quenching the melt in cold water. The required proportions of $\mathrm{HgI}_{2}$ and $\mathrm{As}_{2} \mathrm{~S}_{3}$ for glass synthesis were also sealed in silica tubes and homogenized in a rocking furnace at $1100 \mathrm{~K}$ for $24 \mathrm{~h}$. The melt was then cooled down to $950 \mathrm{~K}$ and quenched in air. The $\left(\mathrm{HgI}_{2}\right)_{x}\left(\mathrm{As}_{2} \mathrm{~S}_{3}\right)_{1-x}$ samples were found to be vitreous between $0 \leq x \leq 0.2$. A JEOL JSM-7100F thermal field emission scanning electron microscope equipped with EDX Bruker QUANTAX 800 spectrometers was used to check the glass homogeneity and chemical composition. The results, summarized in Table S1 (Supporting information), confirm that the glasses are uniform and reveal the expected glass composition.

Diffraction Measurements. High-energy X-ray diffraction experiments of liquid $\mathrm{HgI}_{2}$ were carried out using BL04B2 beamline ${ }^{28}$ at Spring-8 (Japan). The measurements were conducted in a silica tube ( $3 \mathrm{~mm}$ OD, $2 \mathrm{~mm}$ ID) using a furnace. The X-ray energy was $113 \mathrm{keV}$, providing data at $Q$ values up to $30 \AA^{-1}$ in a one-dimensional scanning mode using a Ge-detector. The empty silica tube was also measured and used for background intensity subtraction. Further data analysis included absorption, Compton scattering and polarization corrections using standard procedures ${ }^{28}$ giving the total X-ray structure factor $S_{X}(Q)$.

The $\mathrm{HgI}_{2}-\mathrm{As}_{2} \mathrm{~S}_{3}$ glasses were measured using time-of-flight neutron diffraction at the ISIS spallation neutron source (Rutherford-Appleton Laboratory, UK) and high-energy X-ray diffraction at the Advanced Photon Source (Argonne National Laboratory, USA). The GEM diffractometer ${ }^{29}$ at ISIS provides diffraction data over an extended range in reciprocal space up to $50 \AA^{-1}$, leading to a high resolution in real space. The neutron diffraction data corrected ${ }^{30}$ for background and container scattering, self-attenuation, multiple scattering, and inelasticity (Placzek) effects to obtain the total neutron structure factor $S_{N}(Q)$. High-energy X-ray diffraction experiments of glasses were conducted at the 6-ID-D beamline. ${ }^{31}$ The X-ray energy 
was $100 \mathrm{keV}$, providing data at $Q$ values up to $30 \AA^{-1}$. A 2D setup was used for data collection with a Perkin Elmer model $1621 \mathrm{X}$-ray area detector. The two-dimensional diffraction patterns were reduced using the Fit2 $\mathrm{D}^{32}$ software. The measured background intensity was subtracted, and corrections were made for the different detector geometries and efficiencies, sample selfattenuation, and Compton scattering using standard procedures ${ }^{33}$ providing the $S_{X}(Q)$.

Raman Spectroscopy Measurements. Raman spectra were collected at room temperature using a LabRam HR spectrometer (Jobin Yvon Horiba Group) equipped with a triple monochromator, liquid nitrogen cooled CCD detector and a microscope. Raman scattering was excited by a $632.8 \mathrm{~nm}$ He-Ne laser and recorded in the $80-850 \mathrm{~cm}^{-1}$ spectral range, reliable data are above $100 \mathrm{~cm}^{-1}$. To avoid crystallization of the glassy samples, the laser power was set to 0.1 $\mathrm{mW}$ and the acquisition time was 60 to $300 \mathrm{~s}$. Two to three spectra were registered for each sample at different positions to verify the sample homogeneity and the absence of photoinduced phenomena. The spectrometer resolution was $1 \mathrm{~cm}^{-1}$.

Empirical Potential Structure Refinement (EPSR) Modeling. Empirical Potential Structure Refinement ${ }^{34-36}$ was used to create a structural model which is consistent with the measured diffraction data. The EPSR method is based on conventional Monte Carlo algorithm which uses the scattering data to generate an empirical potential. The empirical potential perturbs the starting reference Lennard-Jones potential in a manner that the simulated structure reproduces the experimental measurements as closely as possible. The EPSR simulation box for liquid $\mathrm{HgI}_{2}$ was set up as a cubic box of $66.11 \AA$ side length containing $2000 \mathrm{HgI}_{2}$ molecules at an atomic density of 0.02067 atoms $\AA^{-3}$, corresponding to the experimental number density at $545 \mathrm{~K}$. The Lennard-Jones potential well depth $\varepsilon=1.0 \mathrm{~kJ} \mathrm{~mol}^{-1}$ and length $\sigma=3.0 \AA$ were used as starting parameters for both mercury and iodine. First, the random mixture of molecules was equilibrated at $545 \mathrm{~K}$ using the reference potential alone. Then, the empirical potential was introduced to begin the refinement against the X-ray data until the internal energy stabilization. The final atomistic configuration was obtained after minimizing the fitting factor between experimental and simulated structure factors. When an appropriate fit to the experimental data was reached, the statistics of the simulation was accumulated for thousands of iterations. The simulated intermolecular and intramolecular partial pair distribution functions, as well as bond angle distribution and intramolecular distances were extracted from the final optimized configuration.

DFT Modeling. The DFT calculations have been carried out using Gaussian 16 software. ${ }^{37}$ In order to find a compromise between the cost of the calculations and the accuracy of the results, structural optimization and harmonic vibrational frequency calculations were performed for size-limited clusters. The DFT calculations were carried out with the Becke ${ }^{38}$ three parameters hybrid exchange functional and the Lee-Yang-Parr correlation functional (B3LYP). ${ }^{39}$ The smallcore relativistic pseudo-potential basis set (cc-pVTZ-PP) ${ }^{40}$ and the effective core potentials available in the Environment Molecular Science Library ${ }^{41}$ were employed for cluster geometry optimization and Raman intensity calculations. All the structures were optimized using the tight convergence option ensuring adequate convergence and reliability of computed wave numbers.

Second Harmonic Generation (SHG) Measurements. The SHG was measured by the powder method. ${ }^{42}$ A femtosecond laser Mira Optima 900-D (Coherent) with acousto-optic modulator Pulse Switch in cavity dumping operation mode was used for exciting a SHG in the samples. The 
pulse frequency was $200 \mathrm{kHz}$ and the pulse duration $150 \mathrm{fs}$. The beam energy on the samples was about $20 \mathrm{~nJ}$.

\section{RESULTS AND DISCUSSION}

Liquid Mercury (II) Iodide: Diffraction Results. The X-ray structure factor $S_{X}(Q)$ of liquid mercury (II) iodide measured at $545 \mathrm{~K}$, just above the melting point at $532 \mathrm{~K}$, is shown in Fig. 1. We note a small First Sharp Diffraction Peak (FSDP) at $Q_{0}=0.97 \pm 0.02 \AA^{-1}$, quite narrow principal peak at $1.71 \AA^{-1}$ and distinct oscillations over a wide $Q$-range up to $25 \AA^{-1}$. A Voigt function was used to approximate the background underneath the FSDP,43,44 allowing the subtraction and analysis. The isolated FSDP is shown in the inset of Fig. 1(b).

The observed FSDP reflects intermediate range ordering of $\mathrm{HgI}_{2}$ molecules in the melt at a characteristic periodicity $L_{0} \cong 2 \pi / Q_{0}=6.5 \pm 0.2 \AA$. The derived periodicity $L_{0}$ is comparable with the average intermolecular separation, $2 r_{W S}=6.51 \AA$, estimated from the density and chemical composition using a Wigner-Seitz type equation, $r_{W S}=\sqrt[3]{(3 / 4 \pi) V_{m} N_{A}^{-1}}$, where $V_{m}$ is the molar volume of liquid $\mathrm{HgI}_{2}$ and $N_{A}$ the Avogadro constant.

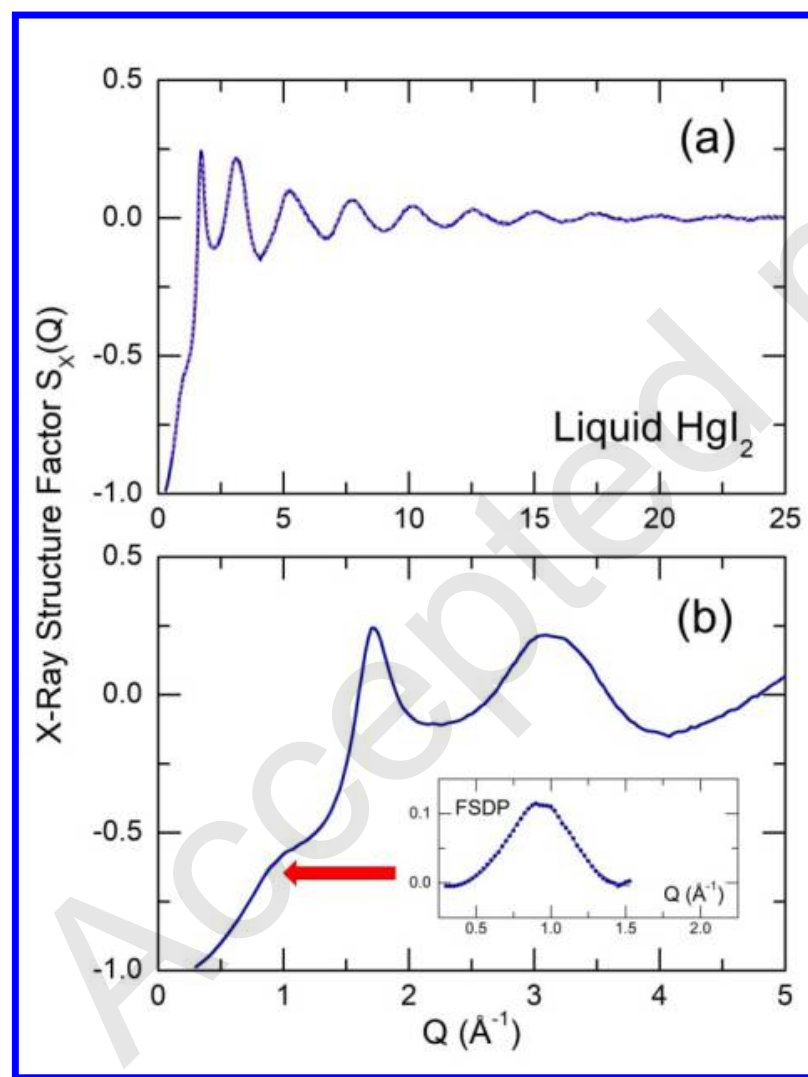

Figure 1. High-energy X-ray structure factor $S_{X}(Q)$ for liquid $\mathrm{HgI}_{2}$ at $545 \mathrm{~K}$ : (a) the entire $Q$ range, (b) the low- $Q$ region; the solid blue line: experiment, the dashed magenta line: Empirical Potential Structure Refinement (EPSR) modeling. The inset shows the isolated First Sharp Diffraction Peak (FSDP) centered at $Q_{0}=0.97 \pm 0.02$ $\AA^{-1}$.

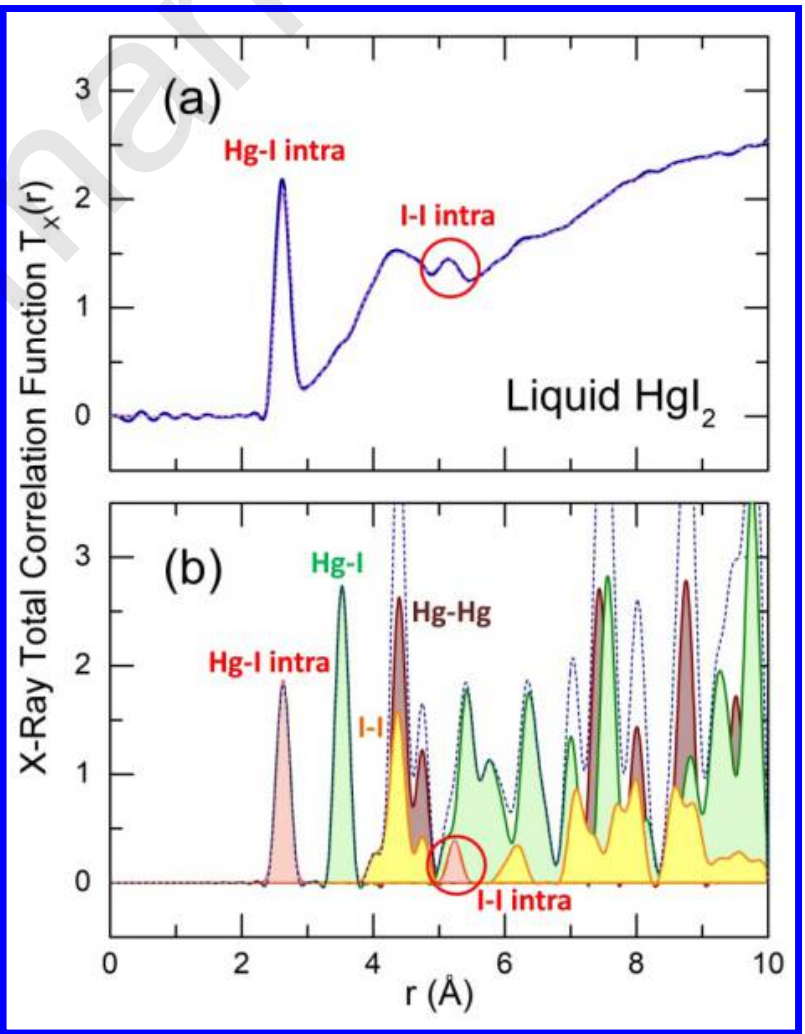

Figure 2. X-ray total correlation functions for (a) liquid $\mathrm{HgI}_{2}$ at $545 \mathrm{~K}$ and (b) the yellow orthorhombic $\mathrm{HgI}_{2}$ polymorph, ${ }^{23}$ consisting of linear $\mathrm{HgI}_{2}$ monomers. The intramolecular separation distances Hg-I and I-I are shown in red. The intermolecular $\mathrm{Hg}-\mathrm{Hg}, \mathrm{Hg}-\mathrm{I}$ and I-I contacts for $\beta$ $\mathrm{HgI}_{2}$ are highlighted in brown, green and yellow, respectively. 
The X-ray total correlation function $T_{X}(r)$ derived through the usual Fourier transform using a Lorch window function ${ }^{45}$ is shown in Fig. 2(a). The peak at $2.62 \AA$ corresponds to Hg-I first neighbors. Both the shortest intramolecular distance and the Hg-I local coordination, $N_{\mathrm{Hg}-\mathrm{I}}=2$, reflect the molecular nature of the melt consisting of triatomic $\mathrm{HgI}_{2}$ monomers. In orthorhombic yellow polymorphs, 19,23 the Hg-I intramolecular separations, $2.623 \pm 0.007 \AA$, are very close to the derived value in contrast to the $\mathrm{Hg}$-I first neighbor distances in tetragonal red $\alpha-\mathrm{HgI}_{2}$, $2.783 \pm 0.003 \AA .^{19}$ A broad asymmetric peak at $4.3 \AA$ corresponds to closest intermolecular contacts. A very important structural feature appears at $\approx 5.15 \AA$. This peak is related to I-I intramolecular separations directly indicating that the $\mathrm{HgI}_{2}$ monomers are bent; the bond angle $\angle \mathrm{I}-\mathrm{Hg}-\mathrm{I} \approx 159^{\circ}$. The Hg-I, Hg-Hg and I-I partials of the orthorhombic yellow polymorph, ${ }^{23}$ calculated from the corresponding cif file using the XTAL program, ${ }^{46}$ Fig. 2 (b), are consistent with the above conclusions.

Liquid Mercury (II) Iodide: EPSR Modeling. The EPSR simulation box containing $2000 \mathrm{HgI}_{2}$ molecules is shown in Fig 3(a). The simulated X-ray structure factor $S_{X}(Q)$ and total correlation function $T_{X}(r)$ appear to be very close to the experimental counterparts hardly distinguishable in Figs. 1(a) and 2(a), where the two data sets are plotted together. The EPSR modeling confirms a non-linearity of the molecular entities. Figure $3(\mathrm{~b})$ shows the derived bond angle distribution centered at $\angle \mathrm{I}-\mathrm{Hg}-\mathrm{I}=156 \pm 2^{\circ}$.

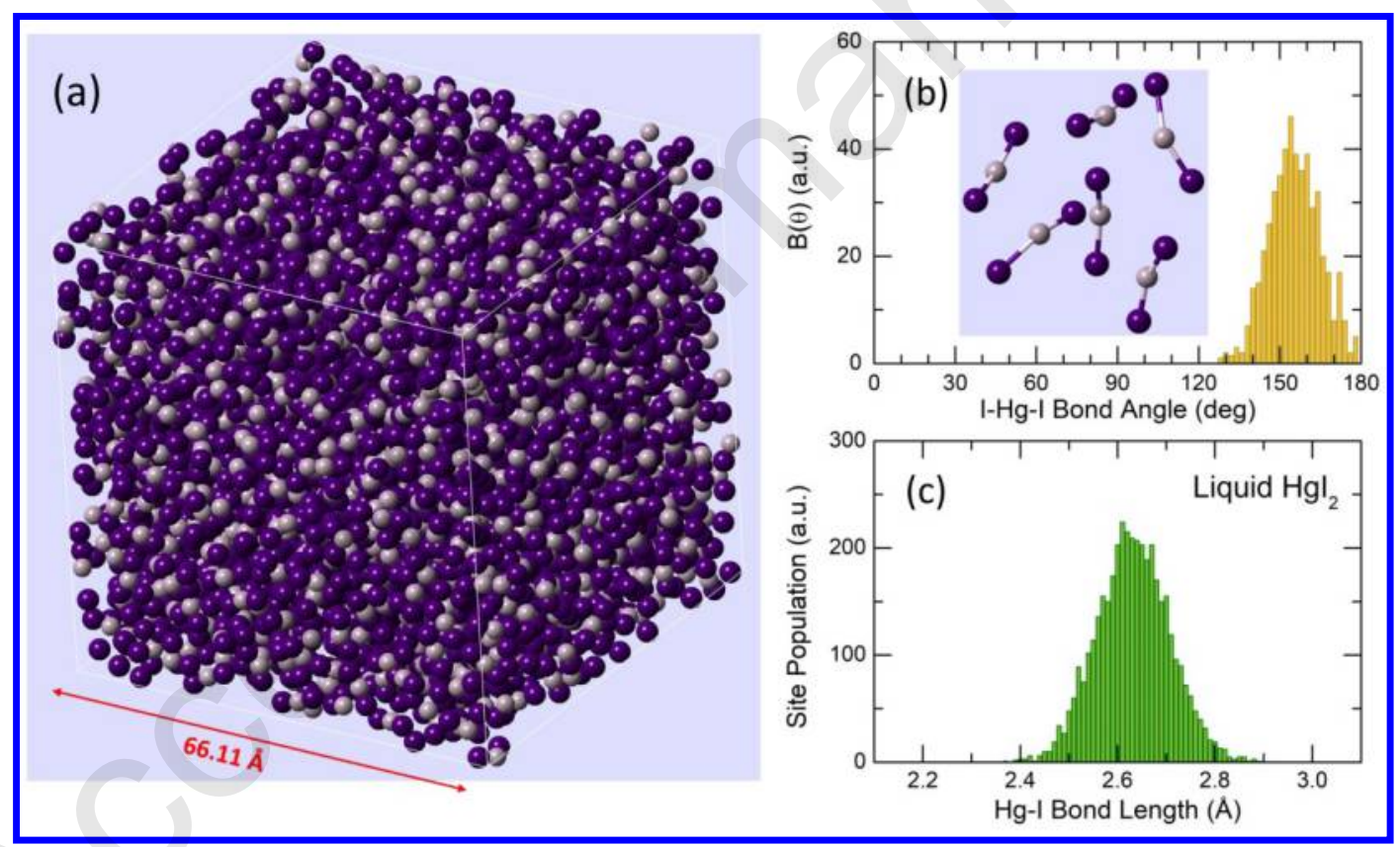

Figure 3. EPSR modeling of liquid mercury (II) iodide: (a) the simulation box containing $2000 \mathrm{HgI}_{2}$ molecules; the box size corresponds to the experimental number density at $545 \mathrm{~K}$; the derived (b) $\angle \mathrm{I}-\mathrm{Hg}-\mathrm{I}$ bond angle distribution $B(\theta)$, and (c) Hg-I intramolecular distances. The inset in Fig. 3(b) shows typical geometry of the bent $\mathrm{HgI}_{2}$ molecules.

The calculated EPSR partials in $Q$ - and $r$-space are shown in Fig 4 . We note the absence of a well-defined FSDP for the partial structure factors suggesting the intermediate range ordering in molten $\mathrm{HgI}_{2}$ is related to the entire molecule with a small preference for the $\mathrm{Hg}$-Hg atomic pairs.

The comparison of intermolecular correlation functions $T_{i j}^{\text {inter }}(r)$ for liquid and orthorhombic mercury (II) iodide, Fig. 5, shows unexpected behavior of the $T_{\mathrm{Hg}-\mathrm{I}}^{\text {inter }}(r)$ partials. In contrast to the $\mathrm{Hg}-\mathrm{Hg}$ and I-I atomic pairs, which exhibit usual thermal broadening with increasing 
$\mathbf{H g I}_{2}-\mathrm{As}_{2} \mathrm{~S}_{3}$ Glasses: Diffraction Results. Bent $\mathrm{HgI}_{2}$ molecules present in the melt can be frozen in an $\mathrm{HgI}_{2}$-contaning glass as solidified supercooled liquid out of thermodynamic equilibrium. In order to verify this possibility, we have studied $\mathrm{HgI}_{2}-\mathrm{As}_{2} \mathrm{~S}_{3}$ glasses. ${ }^{48,49}$ The synthesized $\left(\mathrm{HgI}_{2}\right)_{x}\left(\mathrm{As}_{2} \mathrm{~S}_{3}\right)_{1-x}$ vitreous alloys, $0 \leq x \leq 0.2$, were measured using high-energy X-ray scattering, pulsed neutron diffraction and Raman spectroscopy. Their basic characterization was reported earlier. ${ }^{49}$ 
Typical X-ray $S_{X}(Q)$ and neutron $S_{N}(Q)$ structure factors of $\mathrm{HgI}_{2}-\mathrm{As}_{2} \mathrm{~S}_{3}$ glasses are shown in Fig. 6. Compared to vitreous $\mathrm{As}_{2} \mathrm{~S}_{3}$, the $\mathrm{HgI}_{2}$-contaning glassy alloys are characterized by smaller amplitude of oscillations at $Q<12 \AA^{-1}$, except for the principal peak at $Q_{1} \approx 2.3 \AA^{-1}$, strongly diminished FSDP at $Q_{0} \approx 1.25 \AA^{-1}$, and a significant broadening of the first peaks in $S_{X}(Q)$ and $S_{N}(Q)$ together with their shift to lower scattering vectors. The most changes in $S(Q)$ are directly related to the presence of $\mathrm{HgI}_{2}$ in the glass, as it is shown in Fig. S1 (Supporting information) comparing the $S_{X}(Q)$ of liquid mercury (II) iodide and the structure factors of glasses.
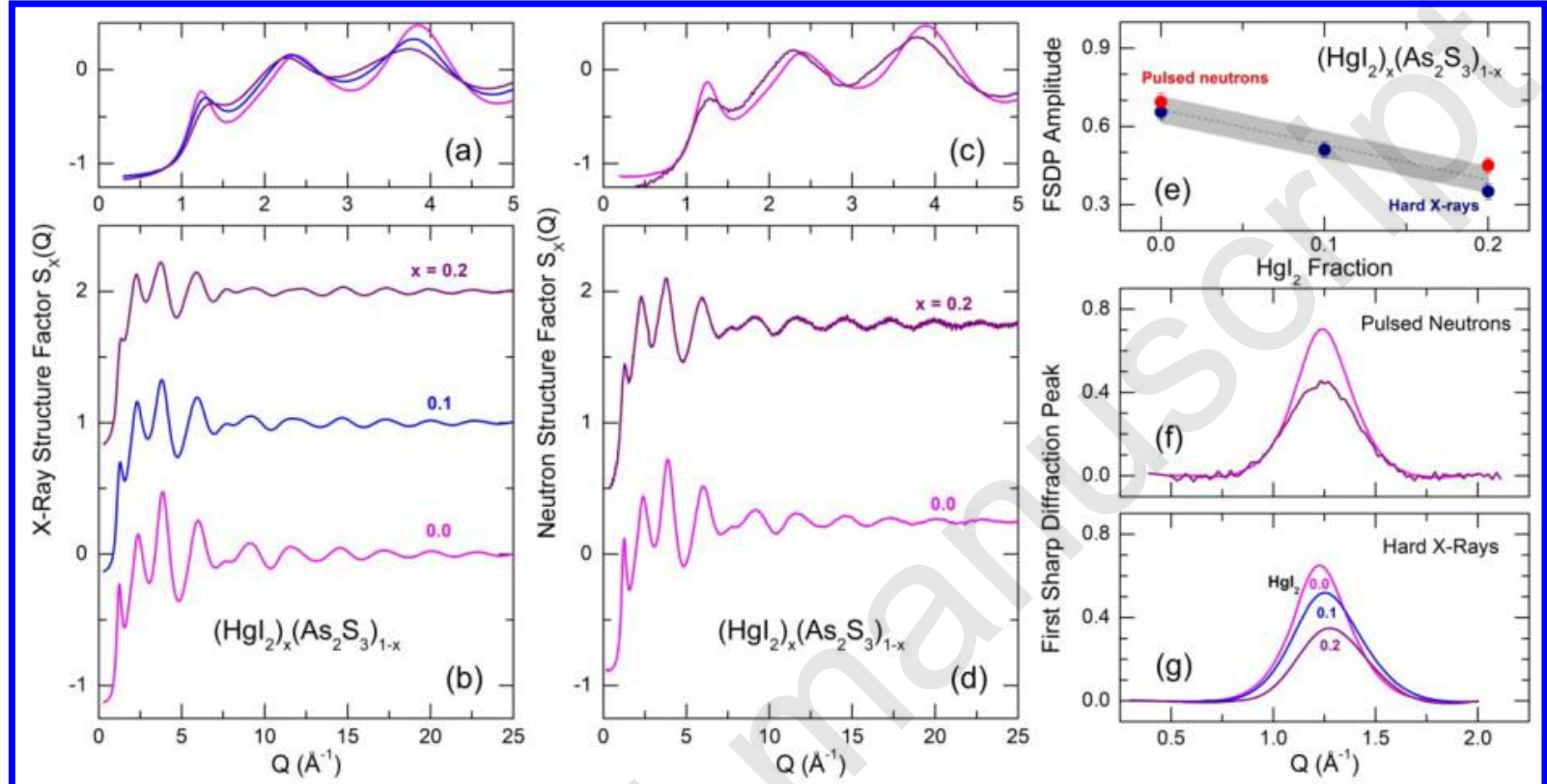

Figure 6. Diffraction studies of $\left(\mathrm{HgI}_{2}\right)_{x}\left(\mathrm{As}_{2} \mathrm{~S}_{3}\right)_{1-x}$ glasses, $Q$-space. X-ray structure factors $S_{X}(Q)$ over $(\mathrm{a})$ limited and (b) extended $Q$-range; neutron structure factors $S_{N}(Q)$ over (c) limited and (d) extended $Q$ range; First Sharp Diffraction Peak (FSDP): (e) compositional dependence of the FSDP amplitude, isolated FSDP in (f) neutron and (g) X-ray diffraction data. The color-coded numbers indicate the mercury iodide fraction in the glass.

The dramatic decrease of the FSDP, Fig. 6(e-g), is related to glass fragmentation, also evidenced by a decrease of the glass transition temperatures from $471 \mathrm{~K}(x=0)$ to $412 \mathrm{~K}(x=0.2)^{49}$ and observed in many metal chalcogenide and chalcohalide systems. ${ }^{50-53}$ In contrast to molecular liquids, the FSDP in network glasses reflects mostly the ring statistics ${ }^{54,55}$ and the FSDP amplitude correlates with population of rings. ${ }^{43,56}$ Mercury (II) iodide additions are effectively destroying the intermediate range ordering in glassy $\mathrm{As}_{2} \mathrm{~S}_{3}$ and transforming the continuous glass network into a patchwork of non- or weakly bonded structural fragments. A linear decrease of the FSDP amplitude $A_{0}(x)$, Fig. $6(\mathrm{e})$, to the limit of $A_{0}(x)=0$, indicates that the intermediate range order characteristic of g- $\mathrm{As}_{2} \mathrm{~S}_{3}$ disappears at $x_{c}=0.55 \pm 0.15$.

The derived X-ray $T_{X}(r)$ and neutron $T_{N}(r)$ total correlation functions of the $\left(\mathrm{HgI}_{2}\right)_{x}\left(\mathrm{As}_{2} \mathrm{~S}_{3}\right)_{1-x}$ glasses are shown in Fig. 7. The first peak at $2.27 \AA$ corresponds to As-S nearest neighbors forming $\mathrm{AsS}_{3 / 2}$ pyramidal units in glassy $\mathrm{As}_{2} \mathrm{~S}_{3 .} .53,57-59$ The amplitude of this peak decreases and a new peak at $2.62 \AA ̊$ emerges and grows with increasing $x$. The second peak is related to Hg-I first neighbors similar to that in liquid mercury (II) iodide, Fig. 2(a). Drastically different peak areas in the X-ray and neutron data of the $x=0.2$ glass are consistent with this assignment since $w_{\mathrm{Hg}-\mathrm{I}}^{N} / w_{\mathrm{As}-\mathrm{S}}^{N}=0.0745$ and $\left\langle w_{\mathrm{Hg}-\mathrm{I}}^{X}\right\rangle /\left\langle w_{\mathrm{As}-\mathrm{S}}^{X}\right\rangle=0.316$, where $w_{i j}^{N}$ and $\left\langle w_{i j}^{X}\right\rangle$ are the neutron and $\mathrm{X}-$ 
ray weighting factors. The angle brackets for the X-ray weightings denote averaging of the $Q$ dependent $w_{i j}^{X}(Q)$ parameters.

The broad slightly asymmetric peak at $\approx 3.5 \AA$ corresponds to second neighbors, and more distant correlations, $r>4 \AA$, reflect changes in the intermediate range ordering. We note a nearly flat high- $r$ range in the $x=0.2$ glass, confirming a progressive disappearance of the distinct intermediate range structure for $\mathrm{g}-\mathrm{As}_{2} \mathrm{~S}_{3}$.

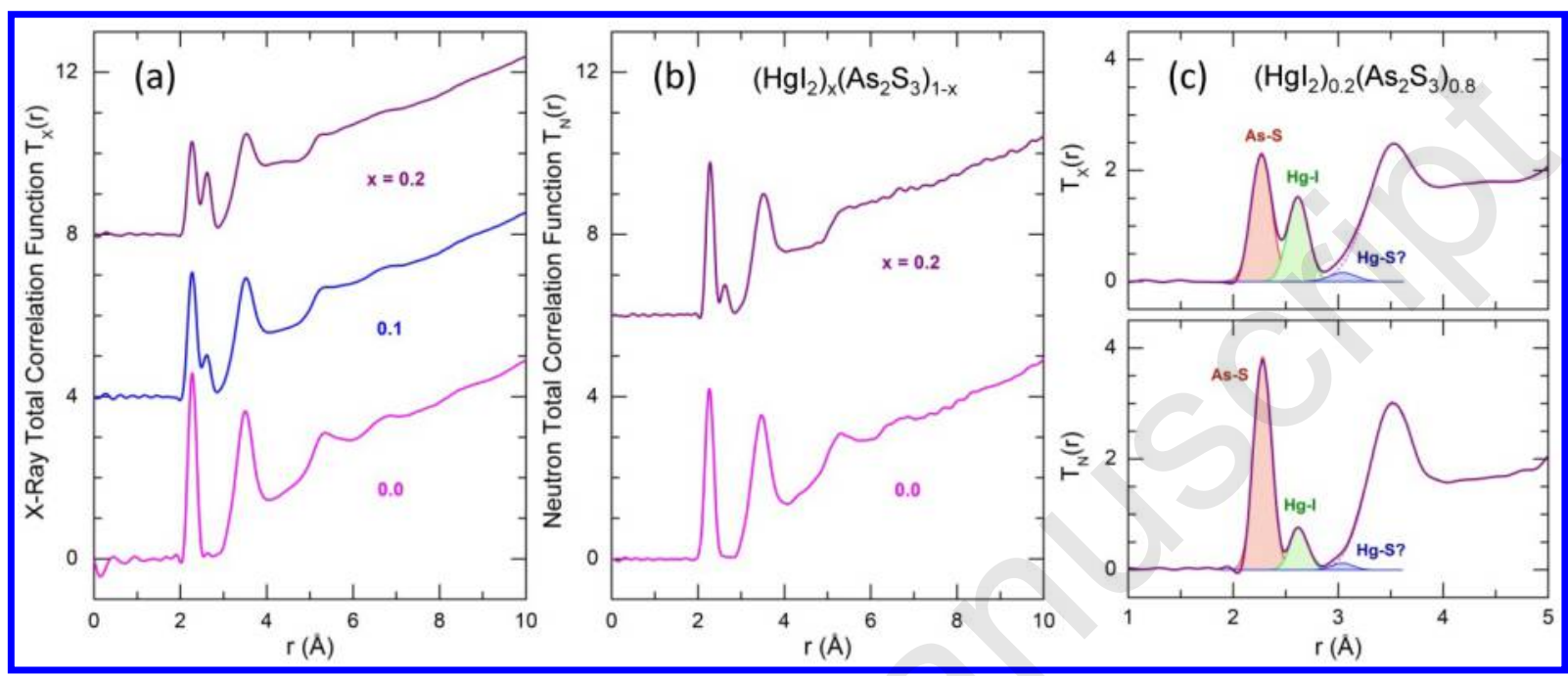

Figure 7. (a) X-ray $T_{X}(r)$ and (b) neutron $T_{N}(r)$ total correlation functions of $\left(\mathrm{HgI}_{2}\right)_{x}\left(\mathrm{As}_{2} \mathrm{~S}_{3}\right)_{1-x}$ glasses, the color-coded numbers indicate the mercury iodide fraction in the glass; (c) fitting the $T_{X}(r)$ and $T_{N}(r)$ functions of the $x=0.2$ glass; the As-S and Hg-I first neighbor correlations are highlighted in red and green, respectively; undefined short second neighbor contacts are shown in blue.

Fitting the derived $T_{X}(r)$ and $T_{N}(r)$ functions confirms the trigonal arsenic coordination by sulfur and two-fold coordinated mercury species with iodine nearest neighbors (Table 1). However, the linear or bent character of $\mathrm{HgI}_{2}$ molecules in glasses cannot be identified without atomistic modeling. The I-I intramolecular correlations are not clearly recognizable in both $T_{X}(r)$ and $T_{N}(r)$.

Table 1. First neighbor distances $r_{i j}$ and local coordination numbers $\boldsymbol{N}_{i j}$ for As-S and Hg-I atomic pairs in $\mathrm{HgI}_{2}-\mathrm{As}_{2} \mathrm{~S}_{3}$ glasses.

\begin{tabular}{ccccc}
\hline $\mathrm{HgI}_{2}$ fraction & $r_{\mathrm{As}-\mathrm{S}}(\AA)$ & $N_{\mathrm{As}-\mathrm{S}}$ & $r_{\mathrm{Hg}-\mathrm{I}}(\AA)$ & $N_{\mathrm{Hg}-\mathrm{I}}$ \\
\hline & & Neutron diffraction & & - \\
\hline 0.0 & $2.27(1)$ & $2.95(10)$ & - & $1.96(10)$ \\
\hline 0.2 & $2.28(1)$ & $2.98(10)$ & $2.62(1)$ & - \\
\hline 0.0 & & High-energy X-ray diffraction & - & $1.95(10)$ \\
0.1 & $2.27(1)$ & $2.94(10)$ & $2.61(1)$ & $2.03(10)$ \\
0.2 & $2.27(1)$ & $3.02(10)$ & $2.62(1)$ & \\
\hline
\end{tabular}

The mean square deviations of the derived parameters are shown in parentheses.

We should also note short second neighbor correlations at $\approx 3.05 \AA$, highlighted in Fig. 7 (c) in blue. They seem to be related to mercury since more visible in the X-ray data. 
$\mathrm{HgI}_{2}-\mathrm{As}_{2} \mathrm{~S}_{3}$ Glasses: Raman Studies and DFT Modeling of the Spectra. Typical Raman spectra of the $\left(\mathrm{HgI}_{2}\right)_{x}\left(\mathrm{As}_{2} \mathrm{~S}_{3}\right)_{1-x}$ glasses are shown in Fig. 8 taking the end members, $x=0$ and $x=0.2$, as an example. Glassy $\mathrm{As}_{2} \mathrm{~S}_{3}$ shows usual broad asymmetric spectral envelope centered at $340 \mathrm{~cm}^{-1}$ and corresponding to multiple As-S stretching vibrations.60-63 In addition to the main spectroscopic feature, weak S-S and As-As stretching modes appear to be visible at 490 and 235 $\mathrm{cm}^{-1}$, indicating a small chemical disorder in stoichiometric $\mathrm{As}_{2} \mathrm{~S}_{3}, 2-3 \%$ according to Ref. [64,65]. Low-intensity bending and deformation vibrations are observed below $200 \mathrm{~cm}^{-1}$.

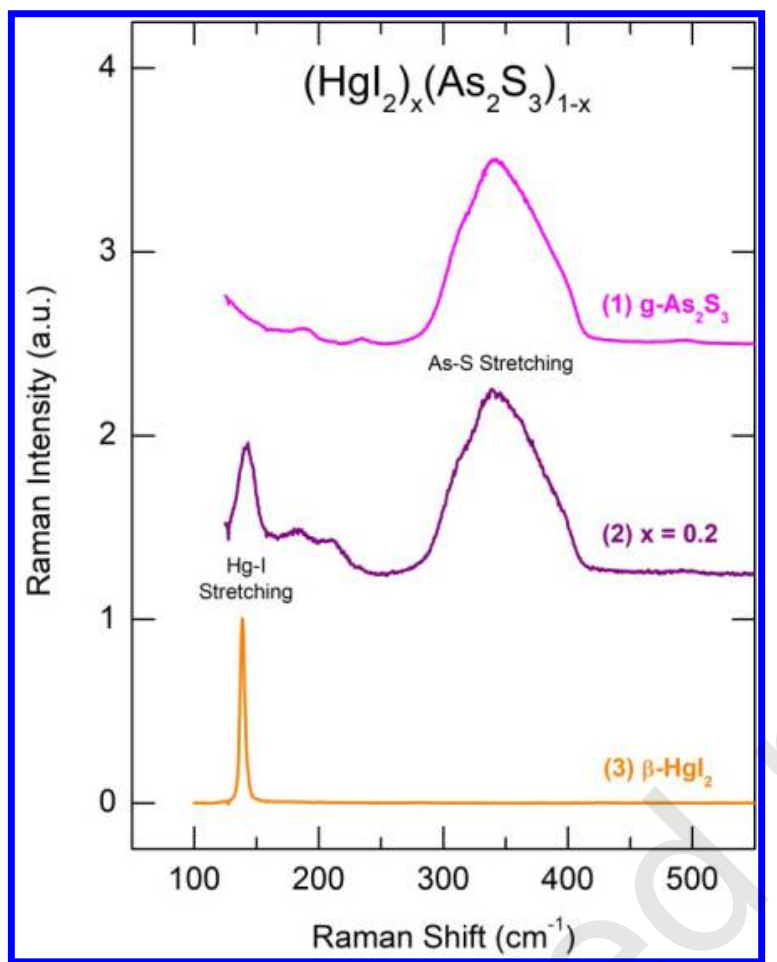

Figure 8. Typical Raman spectra of $\left(\mathrm{HgI}_{2}\right)_{x}\left(\mathrm{As}_{2} \mathrm{~S}_{3}\right)_{1-x}$ vitreous alloys: (1) $x=0$ or glassy $\mathrm{As}_{2} \mathrm{~S}_{3}$, (2) $x=0.2$, and (3) metastable yellow $\beta-\mathrm{HgI}_{2}$ at room temperature. The spectra are normalized to the most intense mode.

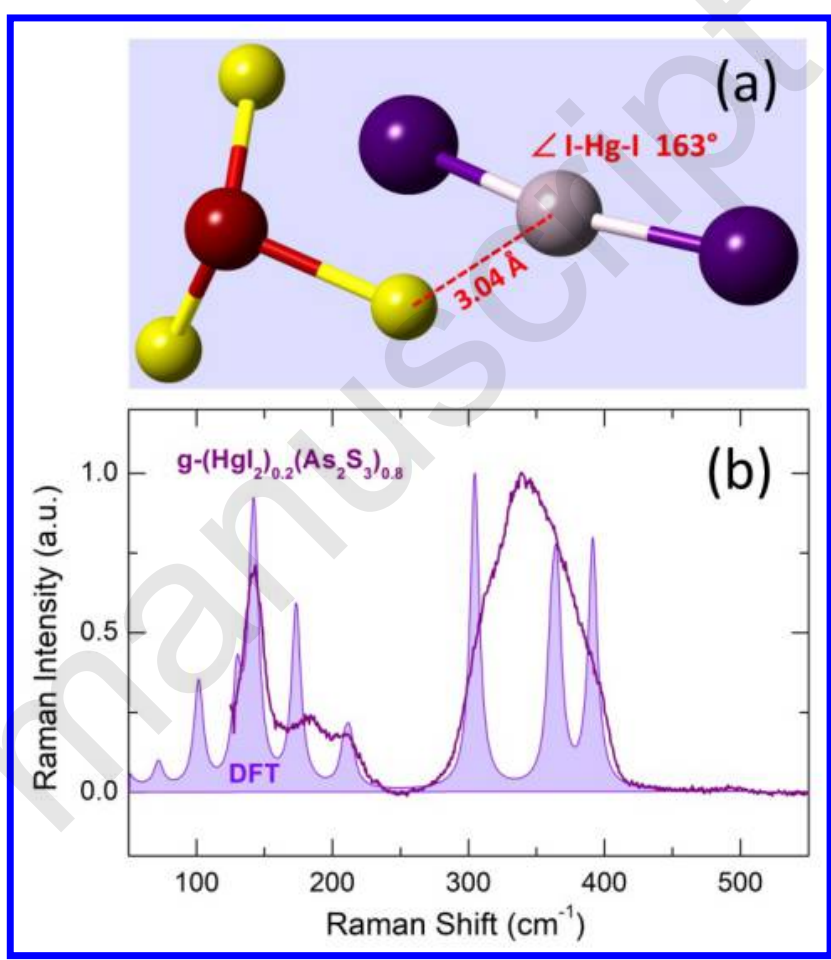

Figure 9. DFT modeling of an interacting system consisting of (a) $\mathrm{AsS}_{3}$ pyramid and $\mathrm{HgI}_{2}$ monomer; (b) the DFT Raman spectrum. The terminal H-species for the $\mathrm{AsS}_{3}$ cluster are omitted and the H-related vibrations are removed from the spectrum.

New low-frequency features appear and grow with increasing $x$ in the $\left(\mathrm{HgI}_{2}\right)_{x}\left(\mathrm{As}_{2} \mathrm{~S}_{3}\right)_{1-x}$ glasses. The most intense mode at $143 \mathrm{~cm}^{-1}$ corresponds to symmetric Hg-I stretching similar to the $v_{1}$ $\left(\Sigma_{g}^{+}\right)$fundamental in yellow mercury (II) iodide $\left(137 \mathrm{~cm}^{-1}\right.$ at room temperature $\left.{ }^{26}\right)$ and triatomic molecules in the vapor phase $\left(157 \mathrm{~cm}^{-1}\right.$ at $\left.728 \mathrm{~K}^{18}\right)$. The Raman spectrum of the obtained metastable $\beta-\mathrm{HgI}_{2}$ at room temperature is also shown in Fig 8, consistent with the reported results. $16-18,25-27$ The DFT modeling reproduces well both the Raman and infrared spectra of the isolated monomer as well as the geometry of the linear $\mathrm{HgI}_{2}$ triatomic molecule, Fig. S2 and Table S2 (Supporting information). Only the $v_{1}\left(\Sigma_{g}^{+}\right)$symmetric Hg-I stretching is Raman-active for the linear monomer of the $D_{\infty h}$ symmetry, confirmed by the Raman data for metastable yellow $\beta-\mathrm{HgI}_{2}$.

Two additional low-frequency Raman modes are observed in the spectra of glasses, also increasing with $x$. The feature at $212 \mathrm{~cm}^{-1}$ is reminiscent of asymmetric Hg-I stretching, which is only IR-active in the linear triatomic molecule, Fig. S2 (Supporting information). Nevertheless, 
this mode is both IR- and Raman-active in the bent $\mathrm{HgI}_{2}$ entities of the $C_{2 v}$ symmetry. ${ }^{18,27}$ The asymmetric Hg-I stretching frequency changes from $\approx 200 \mathrm{~cm}^{-1}$ in the yellow beta-form to 237 $\mathrm{cm}^{-1}$ in the vapor. ${ }^{18,25-27}$ However, the DFT modeling using relativistic pseudo-potentials shows a remarkable rigidity of the isolated linear $\mathrm{HgI}_{2}$ molecule; the energy increases rapidly on molecule bending, Fig. S3 (Supporting information), in accordance with similar DFT calculations. ${ }^{13,66,67}$

We should note that the $\mathrm{HgI}_{2}$ molecules are not isolated in a glassy matrix experiencing at least van der Waals interactions and giving rise to the network fragmentation. Our previous DFT modeling68 of the vibrational properties in Se-Te glasses has shown a significant role of interchain interactions on the geometry and vibration modes of DFT clusters. Similar approach has been used here. As a result, for an interacting system consisting of $\mathrm{AsS}_{3}$ pyramid and $\mathrm{HgI}_{2}$ monomer, the final optimized DFT configuration yields a bent $\mathrm{HgI}_{2}$ molecule, $\angle \mathrm{I}-\mathrm{Hg}-\mathrm{I}=163^{\circ}$, Fig. 9(a) and Table S3 (Supporting information). The corresponding DFT Raman spectrum reproduces well the experimental glass data, Fig. 9(b), including also the third low-frequency feature at $180 \mathrm{~cm}^{-1}$, related to symmetric As-S bending (umbrella movement) of the interacting $\mathrm{AsS}_{3}$ pyramid. The interactions between $\mathrm{AsS}_{3}$ pyramid and $\mathrm{HgI}_{2}$ monomer are stronger than expected van der Waals forces. The final optimized Hg-S intermolecular distance, $3.04 \AA$, appears to be intermediate between the sum of the van der Waals radii, ${ }^{47} r_{v d W}(\mathrm{Hg})+r_{v d W}(\mathrm{~S})=$ $3.85 \AA$ and the interatomic distances in binary crystalline mercury sulfides ${ }^{69,70}$ or mercury thioarsenate and thiogermanate glasses, ${ }^{53,71} 2.30 \AA \leq r_{\mathrm{Hg}-\mathrm{S}} \leq 2.54 \AA$. These rather short intermolecular Hg-S distances might possibly be responsible for the observed but not yet identified second neighbor correlations at $\approx 3.05 \AA ̊$ both in the neutron and X-ray diffraction data, Fig. 7(c). In this case, the average Hg-S coordination number is $N_{\mathrm{Hg}-\mathrm{S}} \approx 1$. In other words, each $\mathrm{HgI}_{2}$ molecule is weakly bonded to one $\mathrm{AsS}_{3}$ pyramid implying that all As-related units will be connected to mercury (II) iodide monomers at $x_{c}=2 / 3$. The estimated critical concentration $x_{c}$ is consistent with that related to a complete disappearance of the intermediate range order in the glassy $\mathrm{As}_{2} \mathrm{~S}_{3}$ host, Fig 6(e).

We also note that similar local structure was found recently for coordination adduct $\mathrm{HgI}_{2} \cdot \mathrm{As}_{4} \mathrm{~S}_{4}$ consisting of undistorted $\mathrm{As}_{4} \mathrm{~S}_{4}$ cages and bent $\mathrm{HgI}_{2}$ molecules, $\angle \mathrm{I}-\mathrm{Hg}-\mathrm{I}=165.9^{\circ} .7^{72}$ Two different $\mathrm{Hg}$-S intermolecular distances in $\mathrm{HgI}_{2} \cdot \mathrm{As}_{4} \mathrm{~S}_{4}$ were found to be $2.984 \AA$ and $3.236 \AA$.

Second Harmonic Generation (SHG) in Glasses. The bent $\mathrm{HgI}_{2}$ molecules are also noncentrosymmetric raising a question of intrinsic optical non-linearity of the second order, extremely rare in glasses.1-4 Homogeneous vitreous alloys usually do not show non-linear optical phenomena of the second order as the second harmonic generation (SHG) or difference frequency generation (DFG) due to the macroscopically present inversion center. A specific treatment (thermal or optical poling, electron beam irradiation, etc.) is generally used to create the induced optical anisotropy in a glass and allow the SHG or DFG responses, see Ref. [73] for further details. Nevertheless, glassy alkali selenophosphates with chiral polymeric chains were found to exhibit a strong SHG signal without any preliminary treatment. ${ }^{1-4}$ Similar results were obtained for $\mathrm{HgI}_{2}$-containing sulfide glasses (Fig. 10) and a detailed description of the observed phenomenon will be published elsewhere. 


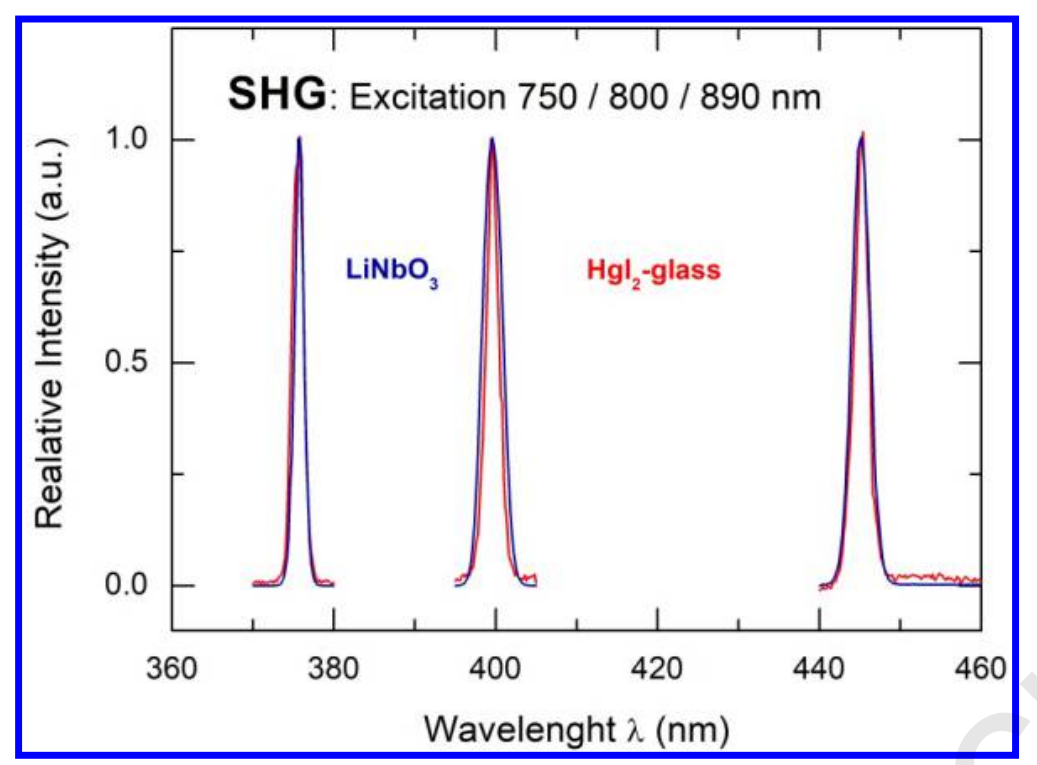

Figure 10. Typical second harmonic generation in a glass with bent $\mathrm{HgI}_{2}$ molecules (the red solid lines) in comparison with a standard non-linear optical crystal $\mathrm{LiNbO}_{3}$ (the blue solid lines). A detailed report will be published elsewhere.

The intrinsic SHG response was only observed for glasses with bent $\mathrm{HgI}_{2}$ molecules embedded in a glass network, and this response was found to be proportional to the $\mathrm{HgI}_{2}$ content (Fig. S4, Supporting information). The SHG measurements as a function of the average glass particle size $\langle r\rangle$, Fig. S5 (Supporting information), have also shown that the SHG amplitude $I(2 \omega)$ decreases with increasing $\langle r\rangle$, roughly following $I(2 \omega) \propto\langle r\rangle^{-1}$. This behavior is typical for NPM materials when $\langle r\rangle \gg \lambda_{c},{ }^{42}$ where NPM stands for nonphase-matchability and $\lambda_{c}$ is the average coherence length. ${ }^{74}$ Consequently, the mercury (II) iodide glasses are not phase-matchable in the studied spectral region, which is close to their fundamental optical absorption edge $E_{g}$ for the SHG frequency $2 \omega$. As a result, the average coherence length, $\lambda_{c}=\lambda / 2\left(n_{2 \omega}-n_{\omega}\right),{ }^{74}$ appears to be very small, $\lambda_{c} \lesssim 1 \mu \mathrm{m}$, where $\lambda$ is the excitation wavelength (750 to $890 \mathrm{~nm}$ ) and the difference of the refractive indices $n_{2 \omega}-n_{\omega} \approx 0.4$, when $2 \omega$ arises in the vicinity of $E_{g}$. However, the phase-matchability strongly depends on the wavelength, ${ }^{1,74}$ and the glasses can be phasematchable at longer $\lambda$ in the mid-IR range.

The non-centrosymmetric geometry of bent $\mathrm{HgI}_{2}$ monomers in a glass network is insufficient for the intrinsic SHG response. Our working hypothesis is based on assumption that orientation of the $\mathrm{HgI}_{2}$ molecules in a glass is non-random within certain mesoscopic domains ensuring a macroscopic SHG effect. A schematic representation of the two extremes in orientation of the bent $\mathrm{HgI}_{2}$ molecules is shown in Fig. 11. The macroscopic SHG effect will vanish for a totally random orientation, Fig. 11(a). On the contrary, the geometric superposition of microscopic second order susceptibility of bent $\mathrm{HgI}_{2}$ molecules in case of preferential molecular orientation within a mesoscopic domain, Fig. 11(b), possibly having a characteristic size of several tens of nanometers, yields a non-zero macroscopic SHG effect, observed experimentally. Similar structural hypothesis was proposed for glassy alkali selenophosphates, where noncentrosymmetric nature of the basic building blocks with chiral helices of ${ }_{\infty}^{1}\left[\mathrm{P}_{2} \mathrm{Se}_{6}^{2-}\right]$ is largely preserved in the glassy phase on a reduced scale, ensuring a strong SHG response. ${ }^{1,2}$ 


\section{CONCLUSIONS}

High energy X-ray diffraction of molten mercury (II) iodide supported by EPSR modeling have shown that the liquid phase is formed by bent $\mathrm{HgI}_{2}$ molecules, the bond angle $\angle \mathrm{I}-\mathrm{Hg}-\mathrm{I}=156 \pm 2^{\circ}$, filling the gap in the molecular architecture of mercury (II) iodide from a low temperature network solid to a high temperature molecular vapor. Molten $\mathrm{HgI}_{2}$ appears to be a van der Waals liquid when all three types of intermolecular correlations are consistent with the sum of the respective van der Waals radii.

High energy X-ray scattering, pulsed neutron diffraction and Raman spectroscopy of $\mathrm{HgI}_{2}-\mathrm{As}_{2} \mathrm{~S}_{3}$ glasses supported by DFT modeling of the vibrational properties have shown that the atomic structure of these solidified supercooled $\mathrm{HgI}_{2}$-containing liquids also consists of the bent $\mathrm{HgI}_{2}$ molecules interacting with $\mathrm{AsS}_{3}$ pyramidal units. The non-centrosymmetric $\mathrm{HgI}_{2}$ entities in hybrid molecular/network glasses open a possibility to design new amorphous optical materials with intrinsic non-linearity of the second order evidenced by the second harmonic generation. Unlimited ability of glasses to be modified with corresponding change in the glass composition, structure and properties, expand perspectives for understanding the fundamental origin of NLO phenomena in isotropic media and in synthesizing new materials with superior NLO properties.

\section{ASSOCIATED CONTENT}

\section{Supporting Information}

Comparison of the X-ray structure factors for $\left(\mathrm{HgI}_{2}\right)_{x}\left(\mathrm{As}_{2} \mathrm{~S}_{3}\right)_{1-x}$ glasses and liquid $\mathrm{HgI}_{2}$; DFT Raman and IR spectra of the linear triatomic $\mathrm{HgI}_{2}$ cluster; relative energy of the $\mathrm{HgI}_{2}$ cluster as a 
function of the bond angle $\angle \mathrm{I}-\mathrm{Hg}-\mathrm{I}$; the $\mathrm{SHG}$ amplitude as a function of the $\mathrm{HgI}_{2}$ content in a glass; the SHG amplitude as a function of the average glass particle size; chemical composition of a $\left(\mathrm{HgI}_{2}\right)_{0.2}\left(\mathrm{As}_{2} \mathrm{~S}_{3}\right)_{0.8}$ glass sample; geometric parameters and DFT vibrational spectra of the isolated $\mathrm{HgI}_{2}$ molecule optimized using relativistic pseudo-potentials; geometric parameters of the DFT optimized interacting system consisting of $\mathrm{AsS}_{3} \mathrm{H}_{2}$ pyramid and $\mathrm{HgI}_{2}$ monomer.

\section{AUTHOR INFORMATION}

\section{Corresponding Author}

*E-mail: Eugene.Bychkov@univ-littoral.fr

\section{ORCID}

M. Kassem: 0000-0003-0512-0004

M. Bokova: 0000-0002-2419-1644

A. Tverjanovich: 0000-0002-0795-8188

D. Fontanari: 0000-0002-5304-5670

D. Le Coq: 0000-0001-7898-3463

A. Sokolov: 0000-0001-9236-5864

P. Masselin: 0000-0002-6718-5498

S. Kohara: 0000-0001-9596-2680

A. C. Hannon: 0000-0001-5914-1295

C. J. Benmore: 0000-0001-7007-7749

E. Bychkov: 0000-0002-3292-1205

\section{Author Contributions}

The manuscript was written through contributions of all authors. All authors have given approval to the final version of the manuscript.

\section{Notes}

The authors declare no competing financial interest.

\section{ACKNOWLEGMENTS}

The authors are grateful to R. Boidin and M. Fourmentin for their participation at the early stage of this work, and to D. Bowron and A. Cuisset for many stimulating discussions related to EPSR and DFT modeling, respectively. We also thank E. N. Borisov for the SHG measurements as a function of the glass particle size and M. Fourmentin for the SEM/EDX analysis. This work was partly supported by Agence Nationale de la Recherche (ANR, France) under Grant No. ANR-15ASTR-0016-01. The experiments at the SPring-8 were approved by the Japan Synchrotron Radiation Research Institute (proposal No. 2014B1197) and supported by the Centre for Advanced Science and Technology (Japan). Work at the Advanced Photon Source, Argonne National Laboratory, was supported in part by the Office of Basic Energy Sciences, U.S. Department of Energy, under Contract No. DE-AC02-06CH1135. A.T. is grateful to SaintPetersburg State University grant No. 12.40.1342.2017. The DFT simulations were carried out 
using the CALCULCO computing platform, supported by SCoSI/ULCO (Service COmmun du Système d'Information de l'Université du Littoral Côte d'Opale).

\section{REFERENCES}

(1) Chung, I.; Kanatzidis, M. G. Metal Chalcogenides: A Rich Source of Nonlinear Optical Materials. Chem. Mater. 2014, 26, 849-869.

(2) Chung, I.; Malliakas, C. D.; Jang, J. I.; Canlas, C. G.; Weliky, D. P.; Kanatzidis, M. G. Helical Polymer $1 / \infty\left[\mathrm{P}_{2} \mathrm{Se}_{6}{ }^{2-}\right]$ : Strong Second Harmonic Generation Response and Phase-Change Properties of Its $\mathrm{K}$ and Rb Salts. L.Am. Chem. Soc. 2007, 129, 14996-15006.

(3) Chung, I.; Jang, J. I.; Malliakas, C. D.; Ketterson, J. B.; Kanatzidis, M. G. Strongly Nonlinear Optical Glass Fibers from Noncentrosymmetric Phase-Change Chalcogenide Materials. L Am. Chem. Soc. 2010, 132, 384-389.

(4) Chung, I.; Kim, M.-G.; Jang, J. I.; He, J.; Ketterson, J. B.; Kanatzidis, M. G. Strongly Nonlinear Optical Chalcogenide Thin Films of APSe6 $(\mathrm{A}=\mathrm{K}, \mathrm{Rb})$ from Spin-Coating. Angew. Chem. Int. Ed. 2011, 50, $10867-10870$.

(5) Ponpon, J. P.; Stuck, R.; Siffer, P.; Schwab, C. Preliminary Results on Mercuric Iodide Nuclear Radiation Detectors. Nucl. Instr. Methods 1974, 119, 197-198.

(6) Schieber, M.; Zuck, A.; Gilboa, H.; Zentai, G. Reviewing Polycrystalline Mercuric Iodide X-Ray Detectors. IEEE Trans. Nucl. Sci. 2006, 53, 2385-2391.

(7) Gilboa, H.; Zuck, A.; Dagan, O.; Vilensky, A.; Breen, B. N.; Taieb, A.; Reisman, B.; Hermon, H.; Zentai, G.; Partain, L.; Street, R.; Ready, S. Medical Imaging with Mercuric Iodide Direct Digital Radiography Flat-Panel X-Ray Detectors. Proc. SPIE 2002, 4784, 315-325.

(8) Jiang, H.; Zhao, Q.; Antonuk, L. E.; El-Mohri, Y.; Gupta, T. Development of Active Matrix Flat Panel Imagers Incorporating Thin Layers of Polycrystalline $\mathrm{HgI}_{2}$ for Mammographic X-Ray Imaging. Phvs. Med. Biol. 2013, 58, 703-714.

(9) Zhang, G.; Li, Y.; Jiang, K.; Zeng, H.; Liu, T.; Chen, X.; Qin, J.; Lin, Z.; Fu, P.; Wu, Y.; Chen, C. A New Mixed Halide, $\mathrm{Cs}_{2} \mathrm{HgI}_{2} \mathrm{Cl}_{2}$ : Molecular Engineering for a New Nonlinear Optical Material in the Infrared Region. L.Am. Chem. Soc. 2012, 134, 14818-14822.

(10) Shi, X.; Ma, Z.; He, C.; Wu, K. Strong SHG Responses Predicted in Binary Metal Halide Crystal HgI 2 . Chem. Phvs. Lett. 2014, 608, 219-223.

(11) Hargittai, M. Molecular Structure of Metal Halides. Chem. Rev. 2000, 100, 2233-2301.

(12) Hargittai, M. Structural Effects in Molecular Metal Halides. Acc. Chem. Res. 2009, 42, 453-462.

(13) Donald, K. J.; Hargittai, M.; Hoffmann, R. Group 12 Dihalides: Structural Predilections from Gases to Solids. Chem. Eur. I. 2009, 15, 158-177.

(14) Spiridonov, V. P.; Gershikov, A. G.; Butayev, B. S. Molecular Structure and Vibrational Potential Function of $\mathrm{HgI}_{2}$ : Electron Diffraction Study. L. Mol. Struct. 1979, 52, 53-62.

(15) Gershikov, A. G.; Spiridonov, V. P. Curvilinearity Effects in Electron Diffraction. L. Mol. Struct. 1981, 75, 291-301.

(16) Loewenschuss, A.; Ron, A.; Schnepp, O. Vibrational Spectra of Group IIB Halides. II. The Halides of Cadmium and Mercury. Chem. Phvs. 1969, 50, 2502-2512.

(17) Clark, R. J. H.; Rippon, D. M. Vapour Phase Raman Spectra of Mercury (II) Chloride, Mercury (II) Bromide and Mercury (II) Iodide. L.Chem. Soc. Faradav Trans. 2 1973, 69, 1496-1501.

(18) Voyiatzis G. A.; Papatheodorou, G. N. Changes of Vibrational Modes Upon Melting Mercury (II) Halides. Ber. Bunsenges. Phvs. Chem. 1994, 98, 683-689.

(19) Jeffrey, G. A.; Vlasse, M. On the Crystal Structures of the Red, Yellow, and Orange Forms of Mercuric Iodide. Inora. Chem. 1967, 6, 396-399.

(20) Hostettler, M.; Birkedal, H.; Schwarzenbach, D. Polymorphs and Structures of Mercuric Iodide, Chimia 2001, 55, 541-545.

(21) Hostettler, M.; Birkedal, H.; Schwarzenbach, D. The structure of Orange $\mathrm{HgI}_{2}$. I. Polytypic Layer Structure. Acta Crystallog. B 2002, 58, 903-913. 
(22) Hostettler, M.; Schwarzenbach, D. The structure of Orange HgI. II. Diamond-Type Structure and Twinning. Acta Crystallog. B 2002, 58, 914-920.

(23) Hostettler, M.; Birkedal, H.; Schwarzenbach, D. The Yellow Polymorphs of Mercuric Iodide ( $\left.\mathrm{HgI}_{2}\right)$. Helv. Chim. Acta 2003, 86, 1410-422.

(24) Parfitt, D. C.; Hull, S.; Keen, D. A.; Crichton, W. High-Pressure Dissociation of Silver Mercury Iodide, $\mathrm{Ag}_{2} \mathrm{HgI}_{4}$. L. Solid State Chem. 2004, 177, 3715-3720.

(25) Adams, D. M.; Appleby, R.; Barlow, J.; Hooper, M. A. Vibrational Spectroscopy at Very High Pressures. 21. Raman and Infrared Study of Mercury (II) Iodide. J. Mol. Struct. 1981, 74, 221-231.

(26) Khilji, M. Y.; Sherman, W. F.; Stadtmuller A.; Wilkinson, G. R. Variable Temperature and Pressure Study of the Raman Spectrum of Five Phases of HgI 2 . L.Raman Spect. 1981, 11, 238-246.

(27) Melveger, A. J.; Khanna, R. K.; Guscott, B. R.; Lippincott, E. R. Low-Frequency Laser-Excited Raman Spectral Study of the Red to Yellow Phase Transition in Mercuric Iodide. Inorg. Chem. 1968, 7, 1630-1634.

(28) Kohara, S.; Itou, M.; Suzuya, K.; Inamura, Y.; Saukrai, Y.; Ohishi, Y.; Takata, M. Structural Studies of Disordered Materials using High-Energy X-Ray Diffraction from Ambient to Extreme Conditions. $L$ Phvs.: Condens. Matter 2007, 19, 506101.

(29) Hannon, A. C. Results on Disordered Materials from the GEneral Materials Diffractometer, GEM, at ISIS. Nucl. Instrum. Methods Phvs. Res., Sect. A 2005, 551, 88-107.

(30) Hannon, A. C.; Howells, W. S.; Soper, A. K. ATLAS: A Suite of Programs for the Analysis of Time-ofFlight Neutron Diffraction Data from Liquid and Amorphous Samples. Inst. Phys. Conf. Ser. 1990, 107, 193-211.

(31) Alderman, O. L. G.; Liška, M.; Macháček, J.; Benmore, C. J.; Lin, A.; Tamalonis, A.; Weber, J. K. R. Temperature-Driven Structural Transitions in Molten Sodium Borates $\mathrm{Na}_{2} \mathrm{O}-\mathrm{B}_{2} \mathrm{O}_{3}$ : X-ray Diffraction, Thermodynamic Modeling, and Implications for Topological Constraint Theory. $L$ Phvs. Chem. C 2016, 120, 553-560.

(32) Hammersley, A. P.; Svensson, S. O.; Hanfland, M.; Fitch, A. N.; Häusermann, D. Two-Dimensional Detector Software: From Real Detector to Idealised Image or Two-Theta Scan. High Pressure Res. 1996, 14, 235-248.

(33) Skinner, L. B.; Benmore, C. J.; Parise, J. B. Area Detector Corrections for High Quality Synchrotron X-ray Structure Factor Measurements. Nucl. Instrum. Methods Phvs. Res. Sect. A 2012, 662, 61-70.

(34) Soper, A. K. Empirical Potential Monte Carlo Simulation of Fluid Structure. Chem. Phvs. 1996, 202, 295-306.

(35) Soper, A. K. Partial Structure Factors from Disordered Materials Diffraction Data: an Approach using Empirical Potential Structure Refinement. Phvs. Rev. B: Condens. Matter Mater. Phvs. 2005, $72,104204$.

(36) Soper, A. K. Computer Simulation as a Tool for the Interpretation of Total Scattering Data from Glasses and Liquids. Mol. Simul. 2012, 38, 1171-1185.

(37) Frisch, M. J.; Trucks, G. W.; Schlegel, H. B.; Scuseria, G. E.; Robb, M. A.; Cheeseman, J. R.; Scalmani, G.; Barone, V.; Mennucci, B.; Petersson, G. A.; et al. Gaussian 16, Revision B.01; Gaussian, Inc.: Wallingford CT, 2016.

(38) Becke, A. D. Density-Functional Thermochemistry. III. The Role of Exact Exchange. J. Chem. Phys. 1993, 98, 5648-5653.

(39) Lee, C.; Yang, W.; Parr, R. G. Development of the Colle-Salvetti Correlation-Energy Formula into a Functional of the Electron Density. Phys. Rev. B: Condens. Matter Mater. Phys. 1988, 37, 785-789.

(40) Feller, D. The Role of Databases in Support of Computational Chemistry Calculations. J. Comput. Chem. 1996, 17, 1571-1586.

(41) Peterson, K. A.; Figgen, D.; Goll, E.; Stoll, H.; Dolg, M. Systematically Convergent Basis Sets with Relativistic Pseudopotentials. II. Small-Core Pseudopotentials and Correlation Consistent Basis Sets for the Post-d Group 16-18 Elements. I. Chem. Phvs. 2003, 119, 11113-11123.

(42) Kurtz, S. K.; Perry, T. T. A Powder Technique for the Evaluation of Nonlinear Optical Materials. J. Appl. Phvs. 1968, 39, 3798-3813. 
Bychkov, E.; Benmore, C. J.; Price, D. L. Compositional Changes of the First Sharp Diffraction Peak in Binary Selenide Glasses. Phvs. Rev. B: Condens. Matter Mater. Phvs. 2005, 72, 172107.

(44) Bytchkov, A.; Cuello, G. J.; Kohara, S.; Benmore, C. J.; Price, D. L.; Bychkov, E. Unraveling the Atomic Structure of Ge-Rich Sulfide Glasses. Phvs. Chem. Chem. Phvs. 2013, 15, 8487-8494.

(45) Lorch, E. Neutron Diffraction by Germania, Silica and Radiation-Damaged Silica Glasses. J. Phys. C: Solid State Phys. 1969, 2, 229-237.

(46) Hannon, A. C. XTAL: a Program for Calculating Interatomic Distances and Coordination Numbers for Model Structures. Rutherford-Appleton Laboratory Report RAL-93-063 (1993).

(47) Batsanov, S. S. Van der Waals Radii of Elements. Inorq. Mater. 2001, 37, 871-885.

(48) Gan, F. Structure, Properties and Applications of Chalcohalide Glasses: a Review. J. Non-Cryst. Solids 1992, 140, 184-193.

(49) Boidin, R. Etude des Propriétés de Conduction et Structurales des Verres du Système $\mathrm{HgI}_{2}-\mathrm{Ag}_{2} \mathrm{~S}$ $\mathrm{As}_{2} \mathrm{~S}_{3}$ : Application en tant que Capteur Chimique, Ph. D. Thesis, Université du Littoral Côte d'Opale, Dunkerque, France (2013).

(50) Lee, J. H.; Owens, A. P.; Pradel, A.; Hannon, A. C.; Ribes, M.; Elliott, S. R. Structure Determination of Ag-Ge-S Glasses using Neutron Diffraction. Phvs. Rev. B: Condens. Matter Mater. Phvs. 1996, 54, 3895-3909.

(51) Bychkov, E.; Price, D. L. Neutron Diffraction Studies of $\mathrm{Ag}_{2} \mathrm{~S}-\mathrm{As}_{2} \mathrm{~S}_{3}$ Glasses in the Percolation and Modifier-Controlled Domains. Solid State Ionics 2000, 136-137, 1041-1048.

(52) Onodera, Y.; Usuki, T.; Nasu, T.; Kohara, S. Structure of Silver Bromide Doped Chalcogenide Glasses. Solid State Ionics 2014, 262, 469-471.

(53) Kassem, M.; Sokolov, A.; Cuisset, A.; Usuki, T.; Khaoulani, S.; Masselin, P.; Le Coq, D.; Neuefeind, J. C. Feygenson, M.; Hannon, A. C.; Benmore, C. J.; Bychkov, E. Mercury Sulfide Dimorphism in Thioarsenate Glasses. I. Phvs. Chem. B 2016, 120, 5278-5290.

(54) Moss, S. C.; Price, D. L. Random Packing of Structural Units and the First Sharp Diffraction Peak in Glasses. In Physics of Disordered Materials; Adler, D., Fritzsche, H., Ovshinsky, S. R., Eds.; Plenum: New York, 1985; pp 77-95.

(55) Vashishta, P.; Kalia, R. K.; Antonio, G. A.; Ebbsjö, I. Atomic Correlations and Intermediate-Range Order in Molten and Amorphous GeSe2. Phvs. Rev. Lett. 1989, 62, 1651-1654.

(56) Micoulaut, M.; Kachmar, A.; Bauchy, M.; Le Roux, S.; Massobrio, C.; Boero, M. Structure, Topology, Rings, and Vibrational and Electronic Properties of $\mathrm{Ge}_{x} \mathrm{Se}_{1-x}$ Glasses across the Rigidity Transition: A Numerical Study. Phys. Rev. B: Condens. Matter Mater. Phvs. 2013, 88, 054203.

(57) Leadbetter, A. J.; Apling, A. J. Diffraction Studies of Glass Structure. V. The Structure of Some Arsenic Chalcogenide Glasses. L. Non-Crvst. Solids 1974, 15, 250-268.

(58) Iwadate, Y.; Hattori, T.; Nishiyama, S.; Fukushima, K.; Mochizuki, Y.; Misawa, M.; Fukunaga, T. Pulsed Neutron Diffraction Study of the Short Range Structure in Amorphous Arsenic Chalcogenides. L Phvs. Chem. Solids 1999, 60, 1447-1451.

(59) Bychkov, E.; Miloshova, M.; Price, D. L.; Benmore, C. J.; Lorriaux, A. Short, Intermediate and Mesoscopic Range Order in Sulfur-Rich Binary Glasses. L. Non-Crust. Solids 2006, 352, 63-70.

(60) Lucovsky, G. Optic Modes in Amorphous $\mathrm{As}_{2} \mathrm{~S}_{3}$ and $\mathrm{As}_{2} \mathrm{Se}_{3}$. Phys. Rev. B: Condens. Matter Mater. Phys. 1972, 6, 1480-1489.

(61) Wágner, T.; Kasap, S. O.; Vlček, M.; Sklenář, A.; Stronski, A. The structure of $\mathrm{As}_{x} \mathrm{~S}_{100-x}$ glasses studied by temperature-modulated differential scanning calorimetry and Raman spectroscopy. $L$. Non-Crust. Solids 1998, 227-230, 752-756.

(62) Kyriazis, F.; Yannopoulos, S. N. Colossal Photostructural Changes in Chalcogenide Glasses: Athermal Photoinduced Polymerization in $\mathrm{As}_{x} \mathrm{~S}_{100-x}$ Bulk Glasses Revealed by Near-Bandgap Raman Scattering. Appl. Phvs. Lett. 2009, 94, 101901.

(63) Kassem, M.; Khaoulani, S.; Cuisset, A.; Le Coq, D.; Masselin, P.; Bychkov, E. Mercury Thioarsenate

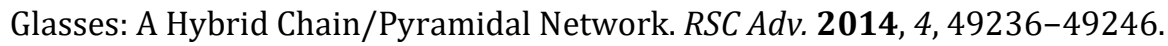

(64) Ewen, P. J. S.; Owen, A. E. Resonance Raman Scattering in As-S Glasses, L. Non-Cryst. Solids 1980, 35-36, 1191-1196. 
(65) Tanaka, K.; Chemical and medium-range orders in $\mathrm{As}_{2} \mathrm{~S}_{3}$ glass, Phys. Rev. B: Condens. Matter Mater. Phys. 1987, 36, 9746-9752.

(66) Kaupp, M.; von Schnering, H. G. Dominance of Linear 2-Coordination in Mercury Chemistry: Quasirelativistic and Nonrelativistic ab Initio Pseudopotential Study of $\left(\mathrm{HgX}_{2}\right)_{2}(\mathrm{X}=\mathrm{F}, \mathrm{Cl}, \mathrm{Br}, \mathrm{I}, \mathrm{H})$, Inorg. Chem. 1994, 33, 2555-2564.

(67) Liao, M.; Zhang, Q.; Schwarz, W. H. E. Properties and Stabilities of $\mathrm{MX}, \mathrm{MX}_{2}$, and $\mathrm{M}_{2} \mathrm{X}_{2}$ Compounds ( $\mathrm{M}=\mathrm{Zn}, \mathrm{Cd}, \mathrm{Hg} ; \mathrm{X}=\mathrm{F}, \mathrm{Cl}, \mathrm{Br}, \mathrm{I})$, Inorg. Chem. 1995, 34, 5591-5605.

(68) Tverjanovich, A.; Cuisset, A.; Fontanari, D.; Bychkov, E. Structure of Se-Te Glasses by Raman Spectroscopy and DFT Modeling. I.Am.Ceram. Soc. 2018, 101, 5188-5197.

(69) Schleid, T.; Lauxmann, P.; Schneck, C. Roentgenographische Einkristalluntersuchungen an alphaHgS (Zinnober). Z. Kristallogr. 1999, 16, 95.

(70) Rodic, D.; Spasojevic, V.; Bajorek, A.; Onnerud, P. Similarity of Structure Properties of $\mathrm{Hg}_{1-x} \mathrm{Mn}_{x} \mathrm{~S}$ and $\mathrm{Cd}_{1-x} \mathrm{Mn}_{x} \mathrm{~S}$ (Structure Properties of HgMnS and CdMnS), L. Magn. Magn. Mater. 1996, 152, 159-164.

(71) Zaiter, R.; Kassem, M.; Fontanari, D.; Cuisset, A.; Benmore, C. J.; Bychkov, E. Ionic Transport and Atomic Structure of AgI-HgS-GeS 2 Glasses. Pure Appl. Chem. 2019, in press. DOI: 10.1515/pac2019-0103.

(72) Bräu M. F.; Pfitzner, A. $\mathrm{HgI}_{2} \cdot \mathrm{As}_{4} \mathrm{~S}_{4}$ : An Adduct from $\mathrm{HgI}_{2}$ Molecules and Undistorted As $\mathrm{S}_{4}$ Cages. Angew. Chem. Int. Ed. 2006, 45, 4464-4467.

(73) Nazabal, V.; Kityk, I. Second Harmonic Generation in Chalcogenide Glasses. In Chalcogenide Glasses: Preparation, Properties and Applications; Adam, J.-L., Zhang, X., Eds.; Woodhead Publ.: Oxford, 2014; pp. 509-561.

(74) Fox, M. Optical Properties of Solids, Oxford University Press: Oxford, 2001. 

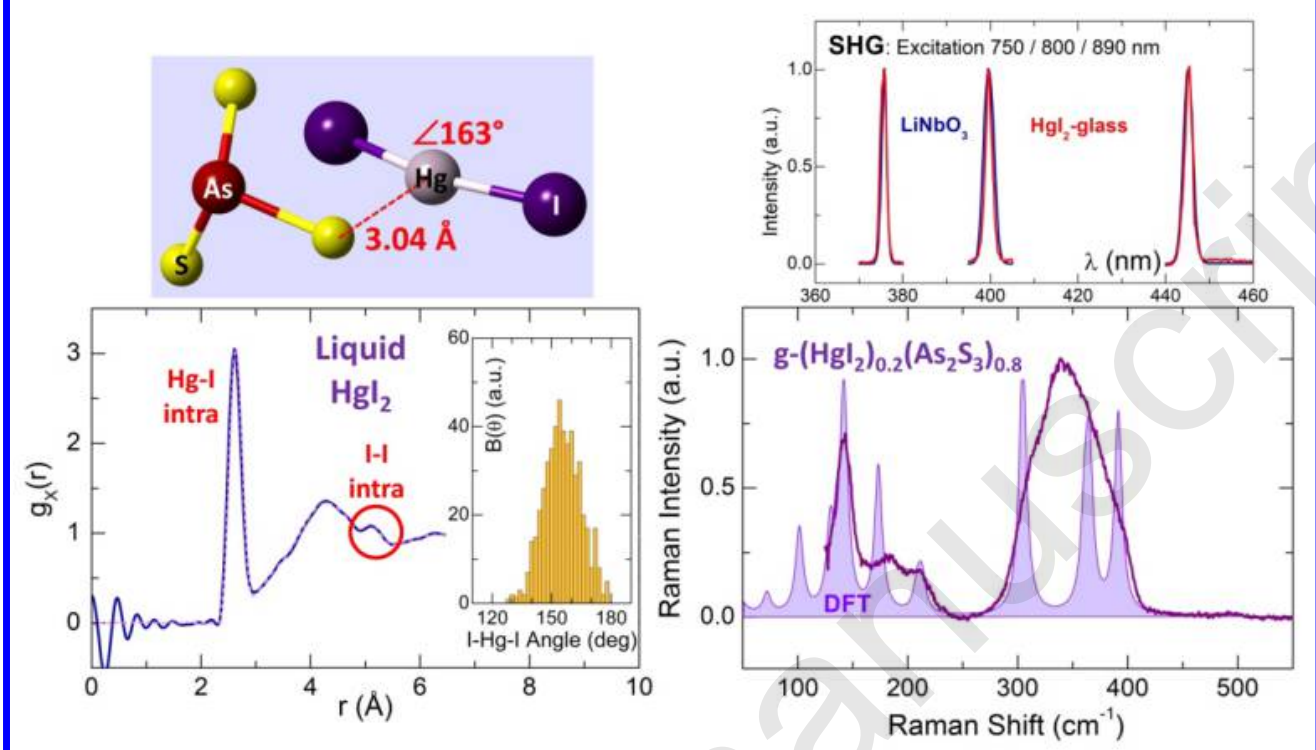

$254 \times 190 \mathrm{~mm}(300 \times 300$ DPI $)$ 